\title{
Leading innovations and investments into the new energy technologies
}

\author{
Anetta Zielińska \\ Wrocław University of Economics \\ Komandorska str. 118/120, 53-345, Wrocław \\ Poland \\ e-mail: anetta.zielinska@ue.wroc.pl \\ Igor Britchenko \\ State Higher Vocational School Memorial of Prof. Stanislaw Tarnowski \\ Henryka Sienkiewicza 50, 39-400, Tarnobrzeg \\ Poland \\ e-mail: ibritchenko@gmail.com \\ Piotr Jarosz \\ Faculty of Management, Higher Socio-Economic School in Przeworsk \\ Gimnazjalna str. 35, 37-200, Przeworsk \\ Poland \\ e-mail: wssg_expert@poczta.pl
}

\begin{abstract}
This paper focuses on the novel and leading innovations and investments into the new energy technologies. Energy issues, including sustainability, energy security and energy dependency are probably one of the most crucial and critical issues that humanity must face at the moment. Recent global challenges, such as climate change and the rise of the "green" energy (represented by the increasing deployment of the renewable energy sources (RES)), as well as distributed energy generation and platform energy markets (e.g. peer-to-peer (P2P) markets for electricity) that were made possible thanks to the rise of Internet, social networks and sharing economy, all create a demand for the new energy technologies. The leaders in energy innovations, such as Tesla are becoming the true trendsetters who are marking the way for the humankind to go forward.

We provide an overview of the innovative energy technologies that might change the energy market as we know it and discuss their outcomes and possible implications. Moreover, we contemplate the changes that might be caused by the ongoing transition from the fossil fuels to RES. Our results might be of some interests to researchers and stakeholders dealing with energy economics and policy.
\end{abstract}

\section{Introduction}

Looking at the events of the recent few decades, one can clearly see that energy is important not just to livelihood but also to the productivity and economic empowerment. Throughout the history of humankind, societies have evolved with complete reliance on energy and the same shows that energy is an essential aspect of our lives and this an indisputable fact (Valuzis 2015; or Strengers and Nicholls 2017). Humankind has evolved from using wood and coal to using wind energy, petroleum, gas nuclear and solar. These developments can be attributed to the massive innovations and inventions that come with investments in energy technologies (Lisin et al. 2014; Mishenin et al. 2018; or Rogalev et al. 2018). The current society seeks efficiency since its benefits are self-evident. Moreover, the emerging issues such as global warming and climate change have also triggered the need to invest in green energy technologies considering their efficiency and reliability (Obama 2017; or Strielkowski 2017).

Moreover, energy is now blending with information (mostly represented by the ICT and Internet-based technologies) that allow for the effective functioning, operating and optimization of energy markets. Information was supposed to become the energy of the new century, but it is a peculiar symbiosis of energy and information that seem to draw the economic and social development forward (Zielińska 2016; Ragulina et al. 2018; or Vegera et al. 2018).

The goal is to reduce the environmental impact that comes with energy consumption and the related emissions. However, the need for energy emissions is also embedded on the necessity to enhance energy security (Balat 2007). However, it is believed that the next generation energy technologies will have the ability to enhance reliability and 
efficiency of energy generation. Some of the areas that are likely to benefit from energy innovations include transport systems, households and industries. The next generation energy technologies will help serve all these purposes and help achieve the global societal goals and objectives, and these are some of the most critical aspects of energy development and growth. It is on the same basis that there is a need to promote energy efficiency through enhancement innovations and investments into the new energy technologies.

\section{Energy inventions and technologies of the modern era}

Recent research indicates that about $16 \%$ of the world's energy consumption comes from energy sources that are renewable (Chu et al. 2017). However, it is essential to indicate that until recently the available renewable energy sources included hydroelectric power and biomass (Newbery et al. 2018). But, some of the most innovative technological innovations of renewable energy have emerged that have resulted into solar, wind and geothermal energy. These inventions have increased the prospects of having a sustainable energy sources at the global level (Lisin et al. 2015; Lisin et al. 2016). These innovations have also increased the contribution to sustainability of energy consumption (Hanson and Laitner 2004). It is then important to look at some of the most promising energy innovations witnessed in the last decades. It will also be ideal to analyze some of the impacts of some of these energy sources as this will help in the understanding of the concept of sustainable energy inventions and technologies. For that reason, it is important to look at some of the most important and promising energy innovations and inventions of the modern time. Figure 1 below shows the obvious decline in gross inland consumption (represented by the solid fuels) in European Union 28 Member States.

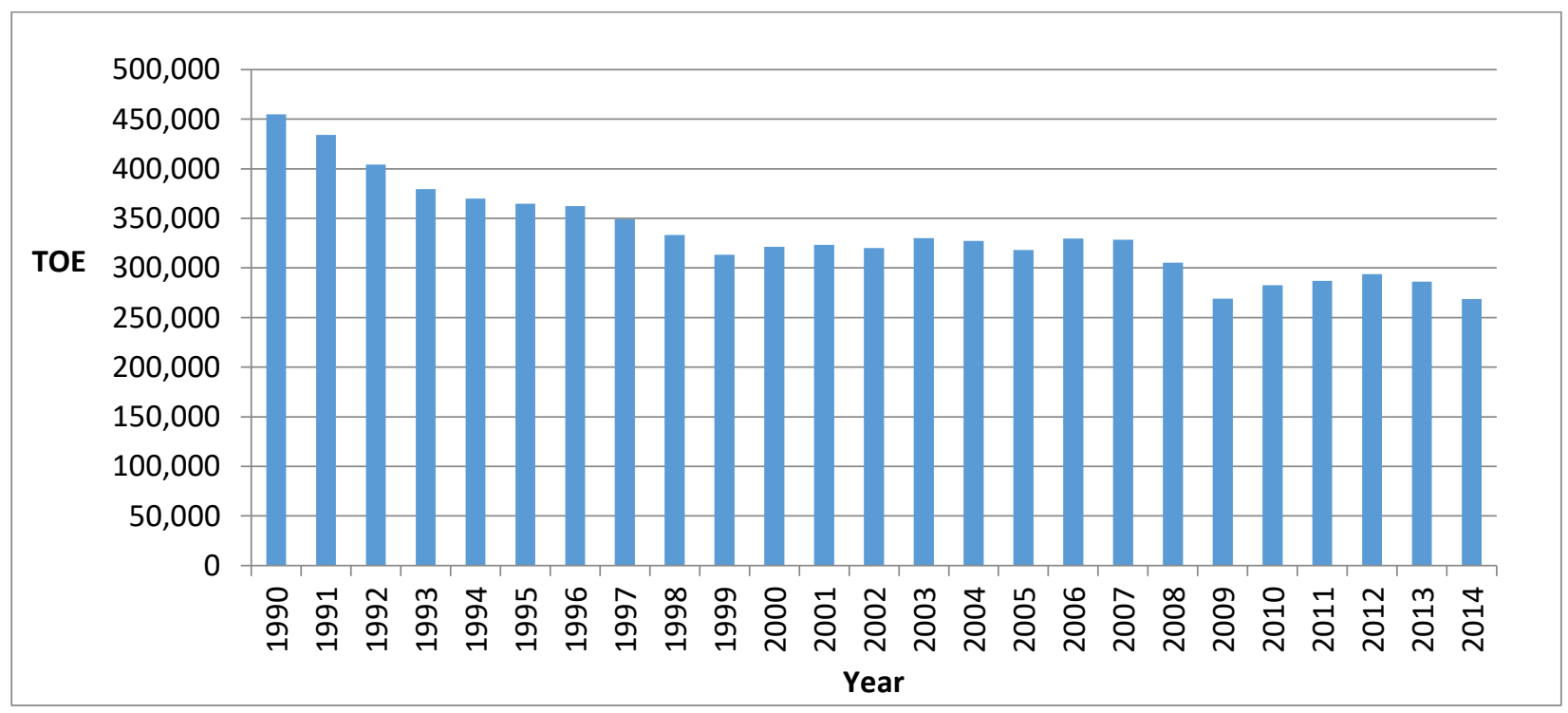

Fig. 1. Gross inland consumption (solid fuels), EU28

Source: Eurostat (2018)

\section{Hydrokinetic power: the direct energy conversion method}

Direct energy conversion method also known as the hydrokinetic power contributed immensely to the need to have a sustainable energy source (Hussain et al. 2017). The ocean tidal waves provide a huge opportunity for green energy. Based on the Electric Power Research report, there are more than 2100 TW of wave energy in the cost of United States alone. Also, another study indicates that the bombardment across the Seven River in the Western England has the prospective to cater for more than 10\% of the nation's electricity needs (El Chaar and Lamont 2013). These are inventions that will prove vital in helping meet the increasing energy demands not just in US and Europe but also in the rest of the world. The tidal power is created through the generators. The turbines are positioned in places with high tides, they then capture the kinetic energy resulting from the motion of the surging ocean and then converts it to electric energy. It is then evident that the Direct Energy Conversion Method (DECM) by the tidal energy is a huge development innovation. The technology, unlike wind energy that uses wind or hydroelectric energy that uses hydraulics, directly 
converts wave energy to electrical energy. The technology also uses low cost linear generated which makes it cost effective. The given invention is a huge progress towards production of cheap energy.

\section{Solar and wind power}

Solar power is another important energy technology that is gaining international acceptance and relevance. The technology uses silicon which is mostly used in manufacturing solar energy-related products. There is an increased demand for solar energy worldwide, and hence experts are seeking feasible substitutes for silicon. Scientists from Israel have created a material that is more expensive compared to silicon but is rather operational when used with a reflective dish (El Chaar and Lamont 2013). From an analytical viewpoint, this is a groundbreaking invention, and the same can prove vital in increasing the efficiency of solar energy, and especially in the long run. From functionality perspective, the reflective dish is positioned in a sunny area and can generate most of utility requirements of a household (Svensson and Berntsson 2011). The equipment contains reflector that is made of mirrors, and they collect an amplified light a thousand times over, and this provides the much-needed solar power. The solar power is then converted to electric energy that can be used in household and even in the industries.

Figure 2 that follows, demonstrate the overall trend of raising solar and wind power generation in the European Union countries.

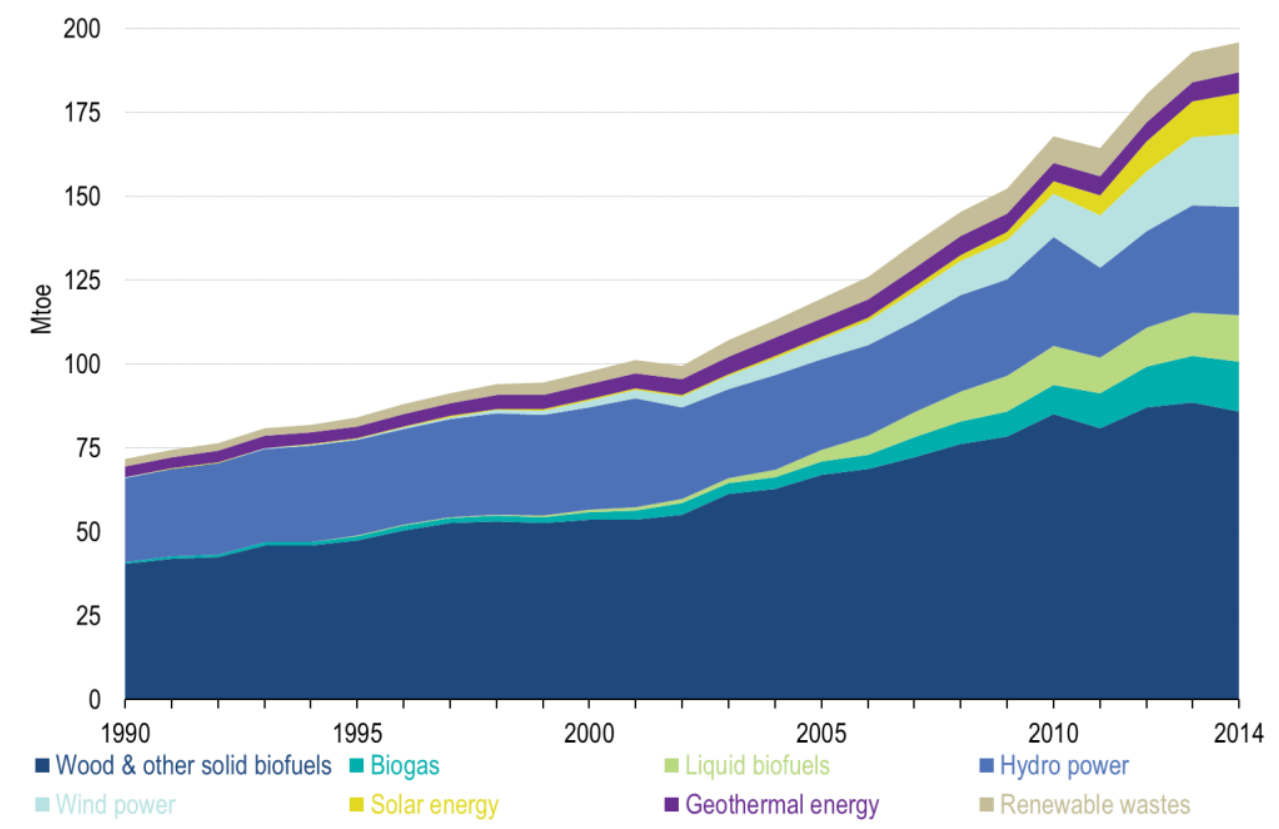

Fig. 2. Energy from renewable sources

Source: European Commission (2018)

There is a projection that the wind energy market will experience consistent growth in the future, and the rate of growth is estimated at 29.6\% within the period 2014-2020. These are statistics according to Transparency Market Research (TMR). It is important, however, to understand that wind energy is viewed as a comparatively stable source of energy and is one of the favorite sources of energy worldwide (Svensson and Berntsson 2011). The RE Power is known as the 'king' of the turbine and is approximately 126-meters and 100-meteres hub height. It is commonly known as the $5 \mathrm{M}$ and denotes the subsequent generation in the large-scale wind. The advantages that come with this type of turbines is that fewer turbines are needed, and efficient wind power can be produced from the offshore. The Multimegawatt Wind Turbines - Wind Power technology is a huge technological breakthrough in the energy sector and points to a possible reduced cost of clean energy in the forgeable future, and that is why it is viewed as one of the best energy sources inventions. 


\section{Biomass power: green crude}

Technological inventions have made it possible for clean energy to be extracted from algae. Some algae contain more than $50 \%$ oil and have zero emission renewable energy sources. The algae can be grown in mass by pharmaceutical companies and organizations, and the same can produce more than 5000 gallons of biodiesel fuel every year. Furthermore, the rate of growth of algae is fast, and it requires massive resources to develop and grow and also maintain, and this makes it cost effective. Based on the assertions of Sapphire Energy, the green crude can be used to make heating oil, gasoline and jet fuels. The Green Crude - Biomass Power is affordable and can replace another source effectively. Looking at the given technology, it is evident that this technology can prove vital in not just reducing energy cost but also contributing to solutions of climate change and global warming.

\section{Flat tower-solar power}

The flat tower-solar power is another important breakthrough in energy innovation and invention. The technology is a huge breakthrough not just in renewable energy but also in architecture. The increasing world population has triggered the building of Skyscrapers in most cities. Some of these structures have dome-like shape at the peak that help in the harvesting of solar energy. The dome is perforated by the use of cell-like skylights that offer direct sunlight to the spaces as well as in the agricultural fields. The idea is that the large surface area of the dome is meant to provide a perfect condition for harvesting of sunlight and the related solar energy which is then converted to electric energy. Theses inventions point to the need for renewable and sustainable energy as supported by the growth of the green energy market. These inventions will help solve the problem of global warming through carbon emissions by providing clean and sustainable energy

Nikola Tesla has been at the center of energy inventions and innovations, however of most significance is the concept of free energy. Tesla came up with a device that would harness free cosmic energy. It was argued by Tesla that it would be the new power to driving the world machineries. The energy is to be derived from the universe also known as the cosmic energy, and the central source would be the sun. The presence of this energy would be limitless in all parts of the world. The free energy concept by Tesla was presented in 1901 as an "Apparatus for the Utilization of Radiant Energy." The main source of this kind of energy would be the sun and other radiant energy and is viewed to would have been a free source of energy. From an analytical viewpoint, the radiant energy as presented by Tesla can be a huge breakthrough in the provision of not just sustainable but also free energy. More needs to be done in ensuring that the proposal of a possible free energy to all as presented by Tesla is achieved.

\section{Conclusions: global energy trends}

Based on the highlighted energy inventions and innovations already mentioned, there has been a massive uptake in various kinds of energy-related technologies. The objective has always been to streamline the use of alternative energy to fossil-based fuel in the generation of energy. The goal has been to come up with not just sustainable but also environmentally friendly sources of energy. The global investment in renewable energy has witnessed 185 growth between the years 2004-2015. The highest share of this growth has been in the developing countries. On the other hand, and from the cost perspectives, the total transaction value related to renewable energy assets grew to $19 \%$.

Finally, these trends point to the crucial necessity for environmentally friendly and green energy both at the local level as well as at the global level. Hence, the inventions and investment in energy technologies are likely to grow and develop given the emerging trends.

\section{References}

Balat M (2007) Global Bio-Fuel Processing and Production Trends. Energy Exploration \& Exploitation 25(3):195218. doi: 10.1260/014459807782009204

Chu S, Cui Y, Liu N (2017) The path towards sustainable energy. Nature Materials 16(1):16. doi: 10.1038/nmat4834

El Chaar L, Lamont LA (2013) Wind Energy Technologies for Distributed Power. Journal of Technology Innovations in Renewable Energy 2(1):1-10. doi: 10.6000/1929-6002.2013.02.01.1 
European Commission (2018) Energy from renewable sources. https://ec.europa.eu/energy/en/topics/renewableenergy/renewable-energy-directive. Accessed 28 Aug 2018

Eurostat (2018) Consumption of energy. https://ec.europa.eu/eurostat/statisticsexplained/index.php/Consumption_of_energy. Accessed 20 Aug 2018

Hanson D, Laitner J (2004) An integrated analysis of policies that increase investments in advanced energyefficient/low-carbon technologies. Energy Economics 26(4):739-755. doi: 10.1016/j.eneco.2004.04.020

Hussain A, Arif SM, Aslam M (2017) Emerging renewable and sustainable energy technologies: State of the art. Renewable and Sustainable Energy Reviews 71:12-28. doi: 10.1016/j.rser.2016.12.033

Lisin E, Lebedev I, Sukhareva E, Komarov, I (2014) Analysis of scenario of structural and technological modernization of the power industry in the context of competitive electricity markets. International Economics Letters 3(3):105-114. doi: 10.24984/iel.2014.3.3.3

Lisin E, Rogalev A, Strielkowski W, Komarov I (2015) Sustainable modernization of the Russian power utilities industry. Sustainability 7(9):11378-11400. doi: 10.3390/su70911378

Lisin E, Sobolev A, Strielkowski W, Garanin I (2016) Thermal efficiency of cogeneration units with multi-stage reheating for Russian municipal heating systems. Energies 9(4):269. doi: 10.3390/en9040269

Mishenin Y, Koblianska I, Medvid V, Maistrenko Y (2018) Sustainable regional development policy formation: role of industrial ecology and logistics. Entrepreneurship and Sustainability Issues 6(1):329-341. doi: 10.9770/jesi.2018.6.1(20)

Newbery D, Pollitt MG, Ritz RA, Strielkowski W (2018) Market design for a high-renewables European electricity system. Renewable and Sustainable Energy Reviews 91:695-707. doi: 10.1016/j.rser.2018.04.025

Obama B (2017) The irreversible momentum of clean energy. Science 355(6321):126-129. doi: $10.1126 /$ science.aam6284

Ragulina Y V, Semenova E I, Zueva I A, Kletskova EV, Belkina E N (2018) Perspectives of solving the problems of regional development with the help of new internet technologies. Entrepreneurship and Sustainability Issues 5(4)890898. doi:10.9770/jesi.2018.5.4(13)

Rogalev A, Komarov I, Kindra V, Zlyvko O (2018) Entrepreneurial assessment of sustainable development technologies for power energy sector. Entrepreneurship and Sustainability Issues 6(1):429-445. doi: 10.9770/jesi.2018.6.1(26)

Strengers Y, Nicholls L (2017) Convenience and energy consumption in the smart home of the future: Industry visions from australia and beyond. Energy Research \& Social Science 32:86-93. doi: 10.1016/j.erss.2017.02.008

Strielkowski W (2017) Social and economic implications for the smart grids of the future. Economics \& Sociology 10(1):310-318. doi:10.14254/2071-789X.2017/10-1/22

Svensson E, Berntsson T (2011) Planning future investments in emerging energy technologies for pulp mills considering different scenarios for their investment cost development. Energy 36(11):6508-6519. doi: 10.1016/j.energy.2011.09.015

Top 5 Innovations of the Decade in Renewable Energy. AltEnergyMag. (2018) Retrieved from https://www.altenergymag.com/article/2015/01/top-5-innovations-of-the-decade-in-renewable-energy/1550/

Valuzis M (2015) Overview of promoting technology - based innovations and investments in R\&D in Lithuania. Applied Technologies and Innovations 11(1):47-51. doi: 10.15208/ati.2015.05

Vegera S, Malei A, Sapeha I, Sushko V (2018). Information support of the circular economy: the objects of accounting at recycling technological cycle stages of industrial waste. Entrepreneurship and Sustainability Issues 6(1):190-210. doi: 10.9770/jesi.2018.6.1(13)

Zielińska A (2016) Information is a market products and information markets. Czech Journal of Social Sciences, Business and Economics 5(4):31-38. doi: 10.24984/cjssbe.2016.5.4.4 